\title{
Difference in mood at work and home. An additional indicator of job satisfaction
}

\author{
Renaud Gaucher $^{1}$ (D) Martijn Burger ${ }^{1} \cdot$ Ruut Veenhoven $^{1,2}$ (D)
}

Accepted: 2 March 2021 / Published online: 29 March 2021

(C) The Author(s) 2021

\begin{abstract}
New techniques for multiple moment assessment allow us to assess how people feel at different times of the day. These techniques are mostly used to assess how well people feel during particular activities, such as during work or childcare. In this paper we focus on the difference in how well people feel at work and at home. The following questions are addressed: 1) How large is the difference in mood at work and at home? 2) How much does the difference in mood at work and at home vary across kinds of people and occupations? 3) Is the difference in mood at work and at home associated with job satisfaction as measured using common general retrospective ratings or does it tap another aspect of job satisfaction? We explore answers to these questions, using data from a diary study in the Netherlands, done using an e-application of the Day Reconstruction Method (DRM) in which 1,410 people provided information about mood experienced in 32,000 episodes. We found that the average difference in mood at work and at home is small in this sample but that it varies across people and occupations. We found a low correlation of the difference in mood with the respondent's retrospective ratings of their general job satisfaction, which suggests that there is more in the phenomena of job satisfaction than is measured using the usual questions on general job satisfaction. This, as yet unrecognized, aspect of job satisfaction is likely to add to information demands behind common measurements of job satisfaction, that is, to indicate the quality of the work conditions and estimate chances to improve worker performance and reduce turnover by making work more satisfying. We suggest an agenda for research in these areas of possible gains.
\end{abstract}

Keywords Affect level · Diary technique · Job satisfaction · Work-life balance · Day reconstruction method

Renaud Gaucher

renaudgaucher@gmail.com

Extended author information available on the last page of the article 


\section{Introduction}

There is a high demand for information about job satisfaction, currently also referred to as 'happiness at work'. One reason for this demand is that the satisfaction of workers is indicative of the objective quality of work conditions and employers would like to know whether a costly improvement of these conditions is necessary. Another reason is that employers expect satisfied workers to be more productive, less inclined to quit and more willing to accept low pay, and for this reason employers want to know whether the current job satisfaction level requires investments to be made to boost this level (Fisher 2003). This information demand has given rise to a lot of research and a search in Google Scholar on 'job satisfaction' yielded 2.860.000 hits on August 31, 2020. In addition to the academic work in this field, there is also a commercial trade in job-satisfaction measurement which serves HR departments of many organizations.

Since satisfaction is something people are aware of, job satisfaction can be measured using self-reports. Most of these self-reports are general estimates in response to questions such as 'How satisfied are you with your job these days?'. Today, job satisfaction is also measured using repeated questions during work hours, such as 'How satisfied do you feel right now?'. We will briefly discuss these techniques including their advantages and disadvantages and subsequently propose a new application for the multiple moment assessment technique.

\subsection{General estimates of one's satisfaction with work}

Most questions on job satisfaction ask respondents to provide a general estimate of their satisfaction, and since the time frame of the questions is typically a period in the past, the answer requires retrospection. In addition to single-item questions, there are many multiple-item and multi-dimensional questionnaires used to tap overall job satisfaction, such as the 'Job in General Scale' (Ironson et al. 1989) or satisfaction with different aspects of the job such as the 'Minnesota Satisfaction Questionnaire' (MSQ) by Weiss et al. (1967).

A key term in these questionnaires is 'satisfaction', which can denote both cognitive contentment and affective experience, depending on the context of the question (e.g. Weiss 2002). There are advantages to distinguishing cognitive contentment from affective experience, especially when assessments of job satisfaction are used as an indication of the quality of work conditions. Cognitive contentment depends to a large extent on comparison and as such on reference points. A worker can be discontented when thinking that the grass is greener elsewhere. Despite this cognitive discontent, the same worker can still feel good at work affectively, which indicates that the working conditions fit the worker's needs, at least according to Veenhoven's theory of affect (Veenhoven 2009; Kainulainen et al. 2018).

Some measures of job satisfaction focus on affect at work. Most questions of this kind draw on the 'circumplex-model' (Russell 1980) of affect. This is the case for the Job-Related Affective Well-Being Scale (Van Katwyk et al. 2000), the Job Affect Scale (Brief et al. 1988; Burke et al. 1989), Warr's (1990) two-dimensional measure of job anxiety-contentment and job depression-enthusiasm, and Daniels' (2000) measure of affective wellbeing at work. Items in these questionnaires typically invite an individual to provide a retrospective estimate of how they have felt at work in the recent past. 


\subsubsection{Advantages of general estimates of job satisfaction}

General self-estimates of job satisfaction are easily elicited and cover a broad range of experiences at work. Over the years, this strand of research has been used to produce benchmark data for different organizations and comparisons with other organizations help employers to raise the level of satisfaction among their employees. General measures of job satisfaction are commonly used in human resource management for this reason.

\subsubsection{Disadvantages of general estimates of job satisfaction}

A substantive problem with general self-estimates of job satisfaction is that these estimates are considerably influenced by the respondent's life satisfaction. A heuristic seems to be, 'I am generally happy, so I must be satisfied with my job'. This top-down effect appears to be stronger than the bottom-up effect, that is the effect of satisfaction with work on satisfaction with life (e.g. Headey et al. 1991). This means that reports of job satisfaction may not reflect the quality of work conditions very well, but rather reflect wider living conditions and innate 'core affect' (Cummins 2014). There is also mounting evidence that job satisfaction predicts performance at work less well than life satisfaction does (e.g. Jones 2006), which means that keys to greater productivity are not only found on the work floor but also in the workers' private life.

A technical problem with self-reports on overall job satisfaction is that retrospection involves several biases, such as greater weight given to salient events, peak-end effect and selective neglect of memories that do not fit values and views on oneself. Vulnerability to such biases is greater the longer the time span over which the estimate is asked to be made and may be greater for cognitive judgements than for remembering affective experience. These distortions have been discussed in detail by Nobel laureate Daniel Kahneman (1999), who consequently pleas for measurement of mood in the moment (Kahneman et al. 2004).

\subsection{Computed averages of multiple assessments of mood in the moment}

How a worker feels at work can also be measured using repeated questions on how the worker feels at certain moments in time. Until recently, the practicability of such multi-moment assessment was low, because it required mood diaries to be kept on paper and the use of pagers. Today, multi-moment assessment is much easier using laptops and smartphones. Two commonly used methods of multiple moment assessment are the Experience Sampling Method (ESM; Larson and Csikszentmihalyi 1983) and the Day Reconstruction Method (DRM; Kahneman et al. 2004).

ESM The Experience Sampling method aims to obtain self-reports for a sample of moments. Participants receive signals on their smartphone (originally an electronic pager). When receiving a signal, participants are asked to answer a few questions on what they are currently experiencing. Examples of such questions are: 'Do you feel good about yourself?' and 'Are you satisfied with how you are doing?' (Csikszentmihalyi and Larson 2014).

DRM The Day Reconstruction Method asks participants to revive memories of the previous day and record these in a diary about this day. This diary is made up of a sequence of episodes defined by a lead activity. Participants must describe each 
episode, answering questions about where the activity took place and who was present during the activity. Once the description of the day is completed, respondents rate how they have felt during each of the activities (Kahneman et al. 2004).

The DRM has been adapted to the work setting (Bakker and Oerlemans 2016). In this adaptation, the focus is on the work day, which is divided into different tasks and breaks. Gaucher has shown for a sample of French sales representatives that the degree of instant satisfaction at work decreased over the work day, that the best moment of the work day was the lunch break, and that the happiest task for the sales representatives was to meet with their clients.

Advantages of DRM over ESM Using ESM provides a 'sample' of daily experiences but does not cover the whole day, since we cannot ask respondents to fill out a questionnaire more than about 6 times a day (Scollon et al. 2009; Ludwigs and Erdtmann 2019). As the sampling of moments in ESM is mostly random, ESM typically generates incomplete information about particular activities, such as having breakfast or shopping. Comparisons of moods during such activities is therefore limited. Using of diary techniques provides a more complete view of an individual's activities during the day, and hence allows for a more elaborate comparison of changing mood during activities on the same day.

\subsubsection{Advantages of multiple moment assessment}

Multiple moment assessment commonly reflects affective experience well and helps us to distinguish the affective component of job satisfaction from the cognitive component. There is mounting evidence that productivity at work is more driven by good mood than by cognitive contentment (e.g. Zelenski et al. 2008), while at the same time a main reason for measuring and promoting job satisfaction is the expectation that happy workers will be more productive (cf. section 1). A focus on momentary mood at work will also reduce the top-down effect, since the reading of one's affective experience in the moment is likely to inhibit the cognitive inference of job satisfaction from life satisfaction.

Technically, multiple moment assessment is less vulnerable to the memory biases, since a respondent reports what he or she feels at a particular moment in time. Although DRM involves retrospection thinking about the day before, the respondents' memories appear to be sufficiently fresh and show little difference with ESM recordings (Dockray et al. 2010; Bylsma et al. 2011; Kim et al. 2013). Since multiple moment assessment can reveal differences in mood across differences in work conditions, it can be used to provide clues about conditions that could be improved to foster job satisfaction.

\subsubsection{Disadvantages of multiple moment assessment}

Multiple moment assessment provides us with precise information about how people feel at a particular moment, but does not provide information about their wider satisfaction over longer periods. Since the technique requires considerable input from a respondent, method effects are likely to occur, such as respondents having greater mood awareness than normal, which tends to raise satisfaction in the medium and long run (Bakker et al. 2020). This may inflate ratings. The technique is also time intensive and for this reason only it is not commonly used, and, as a result, we have little available benchmark data. 


\subsection{Focus on the difference in mood at work and home}

Most studies that use multiple-moment data are used to assess how well people feel during particular activities, thus focusing on their mood level. In this paper we focus on the differences in mood across activities, in particular whether, and to what extent, an individual feels better or worse at work than at home.

\subsubsection{Advantages of focusing on the difference in mood at work and at home}

A main advantage of focusing on the difference in mood at work and at home is that it frees us largely from the top-down problem (cf. section 1.1.1), since mood in different situations is likely to be equally affected by overall satisfaction with life. Likewise, focusing on the difference in mood at work and at home frees us from the measurement problems mentioned in section 1.1.2, the greater weight given to salient events and recent events and duration neglect.

The difference in mood at work and at home of a worker also provides us with an indication of the quality of his or her work conditions together with his or her level of job satisfaction. When a worker usually feels better at home than at work, the low level of job satisfaction is apparently not due to this worker's inability to experience satisfaction, but due to the low quality of his or her work conditions, or at least the to what extent the worker fits in that work environment.

The difference in mood at work and at home is a within-person comparison. A consequence is that the mood difference is not distorted by endogenic variables, such as the workers' personality traits and response tendencies.

The difference in mood at work and at home also gives us an indication of the quality of the work conditions in an unusual way: it does not measure the quality of work conditions in an absolute manner, but in a relative manner. The difference in mood at work and at home shows us that work has a cost in terms of mood, when mood at work is lower than mood at home, and that work is a benefit in terms of mood, when mood at work is higher than mood at home. An employer who wants to improve workers' job satisfaction is not only competing with himself or herself in trying to improve work conditions but with their workers' lives at home. The greater and the more negative the work-home difference in mood is, the more urgent is the need to improve work conditions.

The difference in mood at work and at home may also provide an indication for the probability of absenteeism. If a worker feels much better at home than at work, the worker might be more apt to report sick, even if the worker is satisfied with his/her job. The bigger the difference in mood at work and at home, the stronger the incentive to stay home. Likewise, the difference in mood at work and at home may provide an indication for the probability of turnover, since knowing that one can feel better will make workers more apt to look for a more satisfying job.

\subsubsection{Disadvantages of focusing the difference in mood at work and home}

An evident limitation of using the difference in mood at work and at home is that this difference also depends on the quality of a worker's non-work life. For instance, a worker with a good marriage may feel less well at work than at home despite good working conditions. Reversely, a worker with a bad marriage may feel better at work than at home 
despite poor work conditions. This problem can be addressed by comparing the workers' mood at work with their mood in other situations, such as while commuting, and by comparing the workers' mood during different work activities. Another solution is to control for effects on the workers' mood at home, such as their housing situation and marital satisfaction.

\subsection{Study aims}

Overall, it can be argued that there is no one perfect measure of job satisfaction, but a number of different measures with their own strengths and weaknesses. Together, these measures may provide better answers to the questions that drive job satisfaction research. Along this line, we take a closer look at a measure about which we know least, that is the difference in mood at work at home, and we explore some answers to the following descriptive questions.

1) How large is, on average, the difference in mood at work and home?

2) How much does the difference in mood at work and at home vary across kinds of people and occupations?

3) Is the difference in mood at work and home associated with general estimates of job satisfaction or does it tap into another dimension of job satisfaction?

Note: in this paper we do not address the usual questions of validity and reliability of a measure. We deem all measures valid in the sense that they measure what they are supposed to measure. Rather we discuss the usefulness of the information they provide for employers. We lack data for a systematic comparison of the reliability of the difference in mood at work and at home.

\section{Method}

\subsection{Data set}

For this research, we used data taken from the Happiness Indicator ${ }^{1}$ project, in Dutch: GeluksWijzer, which includes a web-based DRM questionnaire (Bakker et al. 2020). The Happiness Indicator is a combination of self-help website and a long-term scientific follow-up study. Its self-help tools help users find a way of life that fits them. A scientific aim is to get a view of how life-choices work out on the happiness of particular people, e.g. what kind of people become happier after early retirement and what kind of people feel best with what kind of commuting (Lancée et al. 2017). We used this dataset to explore differences in mood at work and at home.

\subsection{Procedure and participants}

Participants were recruited through several channels, including social media (LinkedIn, Facebook, Twitter), Dutch popular magazines, and customer communications from the health insurer VGZ (see Lancée et al. 2017). A disadvantage of the self-selection of respondents is

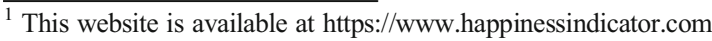


that we cannot generalize our observations to a particular population, such as the general public in the Netherlands, but representativeness is not required in this exploratory study.

The Happiness Indicator provides participants with several 'tools for working on your happiness', among them a Happiness Diary and a Work Orientation Questionnaire. We used the data collected from the users of these two tools. The Happiness Diary is an internet application of the Day Reconstruction Method (DRM) developed by Kahneman et al. (2004). The Work Orientation Questionnaire consists of 62 items on overall job satisfaction, positive and negative emotions at work, engagement at work, burnout and workaholism.

The Work Orientation Questionnaire was a non-mandatory part of the Happiness Indicator. As a consequence, only a part of the respondents used both the Happiness Diary and the Work Orientation Questionnaire. In total, we had 1,410 people that used the Happiness Diary at least once and filled out at least 4 episodes, with at least one activity at home and one activity at work. Most respondents only filled in the diary once. In total, we could draw on 2,720 different diaries containing 32,464 different episodes, and 392 participants used both the diary and the Work Orientation Questionnaire.

Of the 1,410 participants, $82 \%$ were female, $62 \%$ declared they had completed a tertiary education, $78 \%$ reported being in good health and $87 \%$ had paid employment. The average age of the participants was almost 40 years. In addition, $76 \%$ of the respondents indicated they earned an average or above average income. Participants indicated that they worked in health care and welfare (24\%), business and/or financial services (14\%), education (13\%) and government (10\%).

\subsection{Measures}

The dataset included multiple-moment assessments of mood during yesterday's activities and one-time estimates of how a respondent typically felt at work.

\subsubsection{Multiple moment assessment of mood during daily activies}

Participants were asked to list every activity they did the day before responding, such as working, and to report when they started and finished each activity, where each activity was carried out, at work, at home or elsewhere, and with whom, e.g. with colleagues, managers, clients, or with family. Mood levels during each of these activities were rated on a scale ranging from 0 , very unhappy, to 10 , very happy. The data were then used to derive measures of average daily mood during particular activities and in particular places, such as at work and at home. See Figs. 1 and 2.

\subsubsection{Retrospective ratings of subjective wellbeing at work}

In addition to the Happiness Diary, the Happiness Indicator website provides several more options to get a view on one's satisfactions and one of these is the above-mentioned 'Work Orientation Questionnaire', which allows a comparison with the average worker in The Netherlands on three dimensions: overall job satisfaction, positive emotions at work and negative emotions at work.

Overall job satisfaction The questionnaire includes the single question: "Taking everything into account, how satisfied are you with your current job?" Participants could respond to this 

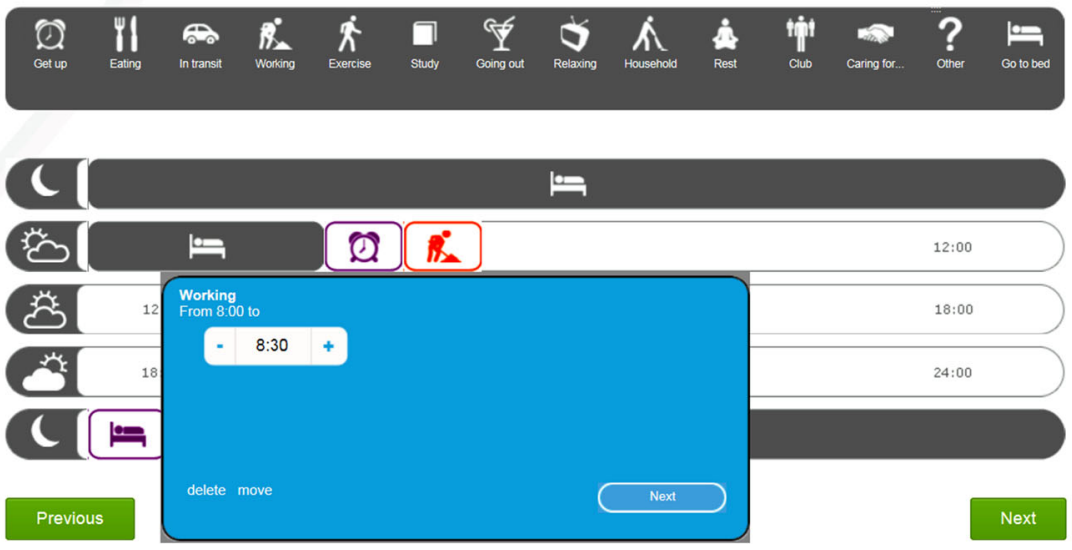

Fig. 1 Example of a diary

question on a 4-point scale ranging from "very dissatisfied" to "very satisfied". Single-item measures can have good validity when the text clearly denotes the concept at which they are aimed (Bergkvist and Rossiter 2007) as is the case for this question.

Positive and negative emotions at work The Work Orientation Questionnaire also presented participants with 16 questions on the emotional states at work they had experienced in the past week, 8 questions about positive emotions and 8 about negative emotions. The positive emotional states listed in the questionnaire are: enthusiastic, calm, happy, relaxed, inspired, peaceful, cheerful, at ease. The negative emotional states listed in the questionnaire are:

\section{Happiness Diary}

How happy did you feel during each of these activities?

Tick each separately and rate how happy you felt during that activity, using the scale 'very unhappy' $(0)$ to 'very happy' $(10)$

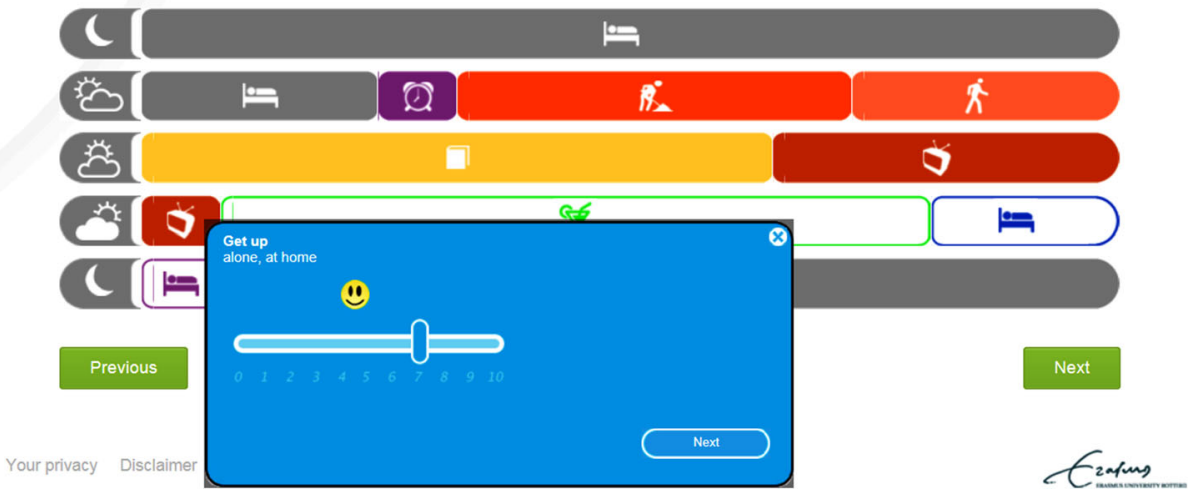

Fig. 2 Rating of how happy the participant felt during an activity 
nervous, depressed, anxious, dejected, tense, despondent, worried, hopeless. Participants could respond on a 7-point scale ranging from "never" to "always". Cronbach's alpha was .92 for positive emotions and .91 for negative emotions.

\subsubsection{Background variables}

All the participants provided information on gender, age, education level, marital status, sector, paid work, health, household income perception, the number of working hours and the number of working days. In the Happiness Indicator, this information was used to generate comparisons with 'similar' people. We used these variables to examine variations in the differences between mood at work and mood at home across subgroups, for example between men and women, young and old people, etc. An overview of the subgroups included in our analyses can be found in Appendix 1 Table 4.

\subsection{Analysis}

Using the Happiness Diary, we estimated the difference in mood at work and at home using the following formula:

$$
\text { Difference in mood at work and mood at home }=\frac{\sum m_{w i} t_{w i}}{T_{w}}-\frac{\sum m_{h j} t_{h j}}{T_{h}}
$$

where $m_{w i}$ represents the mood for the event "work" $\mathrm{i}, t_{w i}$ the duration of the event "work" $\mathrm{i}, T_{w}$ the sum of the duration of events "work", $m_{h j}$ the mood for the home event $\mathrm{j}, t_{h j}$ the duration of this event $\mathrm{j}, T_{h}$ the sum of the duration of all home events.

A goal of the DRM is to approximate the results of continuous, real-time experience measurement (Kahneman et al. 2004). This is why we weighted the mood experienced during each event with the duration of the event.

Univariate difference score If people felt better at work than they did at home, then the difference in mood at work and at home was positive. If they felt worse at work than they did at home, then the difference in mood at work and at home was negative. If they felt equally well at work as at home, our outcome variable took the value of zero.

Multi-variate difference score In addition to the above univariate difference score, we estimated a reduced-form momentary happiness model to gauge the difference in mood at work and mood elsewhere, applying the same methodology as that used by Lancée et al. (2017) in their analysis of the difference in momentary happiness during the commute and at home

$$
\mathrm{M}_{\mathrm{jit}}=\Sigma \mathrm{WORK}_{\mathrm{jit}}+\varepsilon_{\mathrm{ij}}+\lambda_{\mathrm{t}}+\mu_{\mathrm{jit}}
$$

where $\mathrm{M}$ is the self-reported mood level of respondent $j$ on day $i$ at time point $t$; WORK is a set of variables capturing work activity and the various aspects of work; $\varepsilon_{\mathrm{ij}}$ is a vector of respondent-day fixed effects to control not only for time-invariant participant characteristics, such as gender, marital status, income, and level of 
education, but also for the average mood during the day; $\lambda_{t}$ are the time point random effects, while $\mu_{\mathrm{jit}}$ represents the residual error.Please note that we used a withinperson design, where we look at variation of mood within persons within in a day and not between persons. Remember that the main reason to focus on the difference with mood at home instead of on the absolute level of mood at work was to control for the top-down effect (cf. section 1.3.1). Hence our model fitted the main objective of the study: to examine the difference in mood at work and at home. The observations are weighted by the duration of the events.

\section{Results}

\subsection{How large is the difference in mood at work and home?}

\subsubsection{Descriptive statistics}

When we examined the average mood at home, work, and elsewhere, we accounted for the duration of activities. We observed a small, but significant difference in mood at work and at home. Where people rated their mood at work on average at 6.72 , at home this was, on average, a 6.81. Mood during activities elsewhere, predominantly leisure activities, scored the highest average rating 6.99. The difference in mood at work and at home was 0.09 on a range of 0 to 10 .

\subsubsection{Regression results}

Our fixed effects estimations of the influence of work on mood are shown in Table 1. Compared to activities at home and in line with our descriptive statistics, activities at work were significantly associated with lower levels of mood. On average, mood at work was 0.10 points lower on the $0-10$ scale than mood at home, that is $1 \%$ of the possible scale range. At the same time, different activities at work were evaluated differently. Whereas non-work activities at work, lunch, coffee breaks with colleagues, etc., were evaluated higher than the average mood at home, work activities were generally evaluated lower. Average mood for non-work activities at work was 0.26 higher than the average mood at home, the average mood for work activities at work was 0.10 lower than the average mood at home (Table 1, Column 2).

When further exploring to determine to what extent the effect of being at work or at home on mood differed, we found that being at work was especially associated with lower levels of affect when the respondent was alone. Compared to average mood at home, average mood at work for time spent alone was, on average, 0.33 lower (Table 1, Column 3). No statistically significant difference was found for mood during daytime or nighttime work (Table 1, Column 4).

\subsection{How much does the difference in mood at work and home vary across different kinds of people and occupations}

The average difference in mood at work and at home may obscure substantial differences across kinds of people and occupations. Since a goal of the authors of this paper was to explore 
Table 1 Fixed Effects Regression Estimation on Mood: Mood at Work versus Mood at Home

\begin{tabular}{|c|c|c|c|c|}
\hline & $\begin{array}{l}\text { (1) } \\
\text { Baseline }\end{array}$ & $\begin{array}{l}(2) \\
\text { Interaction } \\
\text { Activities }\end{array}$ & $\begin{array}{l}\text { (3) } \\
\text { Interaction Social } \\
\text { Interactions }\end{array}$ & $\begin{array}{l}\text { (4) } \\
\text { Interaction Time } \\
\text { of Day* }\end{array}$ \\
\hline \multicolumn{5}{|l|}{ Location } \\
\hline Home & Reference & Reference & Reference & Reference \\
\hline Work & $-0.10(0.02)^{* * *}$ & & & \\
\hline Work*Work Activities & & $-0.11(0.02)^{* * *}$ & & \\
\hline Work*Non-Work Activities & & $+0.26(0.06)^{* * *}$ & & \\
\hline Work*Alone & & & $-0.33(0.05)^{* * *}$ & \\
\hline Work*With Others & & & $-0.04(0.02)^{*}$ & \\
\hline LWork*Daytime & & & & $-0.10(0.02)^{* *}$ \\
\hline Work*Nighttime & & & & $-0.04(0.10)$ \\
\hline Elsewhere & $+0.19(0.03)^{* * * *}$ & $+0.18(0.03)^{* * *}$ & $+0.19(0.03)^{* * *}$ & $+0.18(0.03)^{* *}$ \\
\hline $\mathrm{R}^{2}$ & 0.45 & 0.46 & 0.46 & 0.45 \\
\hline Respondent and Day Fixed Effects & YES & YES & YES & YES \\
\hline Respondents & 1,410 & 1,410 & 1,410 & 1,410 \\
\hline Observations & 32,264 & 32,264 & 32,264 & 32,264 \\
\hline
\end{tabular}

Note: Robust standard errors in parentheses; *** $\mathrm{p}<0.01, * * \mathrm{p}<0.05, * \mathrm{p}<0.10$. Note: Observations are weighted by duration

possible heterogeneity in work-home mood differences, we split our sample using the available background variables of the respondents. The differences between subgroups are summarized in Table 2, and averages by subgroups are presented in Appendix 2 Table 5.

Overall, our results showed that the difference in mood at work and at home was less negative for older people, singles, people with a higher education, people working part-time, and people working in the public sector; we found no significant differences between men and women, between people with and without children, between different income groups, and between people with paid and unpaid work. ${ }^{2}$

While some of these differences might be explained by the less joyful home situation of some subgroups, e.g. in the case of single people, another part might be driven by work situations that are more mood enhancing. None of the subgroups that we examined felt significantly better at work than at home.

\subsection{How does the difference in mood at work and home relate to other measures of job satisfaction?}

As we have seen in section 2.3.2, the Happiness Indicator data set includes responses to a single question on overall satisfaction with one's work which reads: 'Taking everything into account, how satisfied are you with your current job?'. The time frame was not specified, but respondents are unlikely to interpret this question as pertaining to the present day only and will hence engage in retrospection. This question was answered by 392 participants all of whom had also completed one or more happiness diaries.

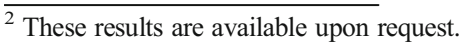


Table 2 Mood at Work (versus Mood at Home) by Subgroup

\begin{tabular}{|c|c|c|c|}
\hline & Mood Difference & Respondents & Observations \\
\hline \multicolumn{4}{|l|}{ Gender } \\
\hline Men & $-0.13(0.05)^{* *}$ & 235 & 5,550 \\
\hline Women & $-0.09(0.02)^{* * *}$ & 1057 & 24,484 \\
\hline \multicolumn{4}{|l|}{ Age } \\
\hline Younger than 35 years & $-0.13(0.04)^{* * *}$ & 475 & 9,917 \\
\hline $35-50$ years & $-0.14(0.04)^{* * *}$ & 539 & 14,149 \\
\hline Older than 50 years & $+0.04(0.05)$ & 278 & 5,968 \\
\hline \multicolumn{4}{|l|}{ Marital status } \\
\hline Single with Children & $-0.06(0.06)$ & 119 & 3,551 \\
\hline Single without Children & $0.00(0.05)$ & 359 & 7,397 \\
\hline Partner with Children & $-0.18(0.05)^{* * *}$ & 293 & 7,618 \\
\hline Partner without Children & $-0.22(0.04)^{* * *}$ & 349 & 7,933 \\
\hline \multicolumn{4}{|l|}{ Family Income } \\
\hline Below Average & $-0.08(0.07)$ & 304 & 7,376 \\
\hline Average & $-0.16(0.04)^{* * *}$ & 477 & 10,534 \\
\hline Above Average & $-0.06(0.03)^{* *}$ & 510 & 12,112 \\
\hline \multicolumn{4}{|l|}{ Education } \\
\hline Lower educated & $-0.15(0.04) * * *$ & 491 & 10,572 \\
\hline High educated & $-0.07(0.03)^{* * *}$ & 801 & 19,462 \\
\hline \multicolumn{4}{|l|}{ Working status } \\
\hline Part-time & $-0.00(0.04)$ & 563 & 12,381 \\
\hline Full-time & $-0.17(0.03)^{* * *}$ & 688 & 15,969 \\
\hline \multicolumn{4}{|l|}{ Job status } \\
\hline Paid & $-0.10(0.02)^{* * * *}$ & 1,120 & 25,746 \\
\hline Unpaid & $-0.10(0.06)^{*}$ & 161 & 3,911 \\
\hline \multicolumn{4}{|l|}{ Sector } \\
\hline Public & $-0.01(0.03)$ & 820 & 19,890 \\
\hline Private & $-0.33(0.04)^{* * * *}$ & 298 & 6,867 \\
\hline
\end{tabular}

Note: Robust standard errors in parentheses; *** $\mathrm{p}<0.01$, ** $\mathrm{p}<0.05, * \mathrm{p}<0.10$. Cases for which information on subgroup category was not available were omitted from the analysis.

The data set also included responses to the questions on experience of 16 emotional states at work, such as 'cheerful' and 'depressed'. The timeframe 'in the past week' also implies a need for retrospective appraisal. Of the 16 questions 8 concerned the experience of positive affect at work and 8 the experience of negative affect at work. We computed an Affect Balance Score for each respondent, subtracting experienced negative affect from experienced positive affect at work. The Affect Balance Scores are available for 392 respondents who also completed at least once the Happiness Diary.

We present the correlations of the retrospective measures, overall job satisfaction and affect at work balance, and the DRM data, average mood during work hours and the difference in mood at work and at home, in Table 3.

All the correlations are statistically significant. The strongest correlation $(+.66)$ was between the two retrospective measures of overall job satisfaction and illustrates that the term 'satisfaction' had a strong affective connotation, in particular when the response options imply frequency of experience. Cognitive contentment was less likely to vary between 'never' and 'frequently'.

The correlation between the two measures of mood in the moment was smaller (+.39) denoting that the difference in mood at work and at home tended to be greater at the higher levels of mood at work. 
Table 3 Correlations between indicators of the quality of work conditions

Multiple moment assessment

\begin{tabular}{ll}
\hline Work-Home & Momentary \\
Mood Difference & feeling at work
\end{tabular}

\begin{tabular}{llll}
\hline Momentary feeling at work & $0.39^{*}$ & 1 & \\
Affect Balance at work & $0.15^{*}$ & $0.29^{*}$ & 1 \\
Overall job satisfaction & $0.21^{*}$ & $0.28^{*}$ & $0.66^{*}$ \\
\hline
\end{tabular}

Retrospective assessment

Affect at work balance

$* \mathrm{p}<0.05$

The average mood at work as assessed using DRM correlated modestly with the retrospective measures of job satisfaction, respectively +.29 with retrospective affect balance, and +.28 with overall job satisfaction.

The smallest correlations we found were between the difference in mood at work and at home and the two retrospective measures of job satisfaction, respectively +.15 with affect at work balance and +.21 with overall job satisfaction. These low correlations confirmed our expectation that the mood difference score taps a different aspect of job satisfaction.

\section{Discussion}

What do our findings tell us about the questions raised in section 1.4? We will first consider the size of the difference in mood at work and at home and the variations in that difference across subgroups. Next, we will explore what information these difference scores add to the commonly used retrospective measures of job satisfaction to improve on knowledge of workers' work-life situations. Finally, we will present suggestions for further research, and applications of the difference in mood measure across situations.

\subsection{Size of the difference}

We stated in section 3.1.1 that the difference in mood at work and at home was 0.09 on a range of 0 to 10 , and a statistically more sophisticated analysis resulted in a similar 0.1 difference on the same range (reported in section 3.1.2). Is this $1 \%$ difference of the possible scale range marginal or considerable?

A comparison of the size of the difference in mood at work and at home with the observed effects of major life changes on life satisfaction can provide us a perspective on the size of the difference in mood at work and at home. Marriage increases one's life satisfaction about $5 \%$, while widowhood lowers an individual's life satisfaction by some $12 \%$ on scale $0-10$ (Bakker et al. 2020).

Accordingly, the $1 \%$ difference in mood at work and at home that we found is small, however, this does not mean that our result and the method used to obtain it is not interesting. One, a small average difference can hide substantial differences in subgroups and greater differences may exist in other populations. Two, our method should be judged independently of the results we obtained. 


\subsubsection{Differences in mood at work and home observed in other studies}

How does the difference in mood at work and at home observed in this study compare with differences in mood at work and at home observed in other studies? We calculated the differences in percentage of the possible scale range in other studies to allow us to compare with our own results.

- In the first DRM study (Kahneman et al. 2004), average affect balance at work was found to be 2.65 on scale $1-7$, positive affect 3.62 , minus negative feelings 0.97 , which was lower for mood among all other activities covered in that study, except commuting. For example, the average affect balance for socializing was 4.02. The difference between affect balance at work and while socializing is -1.37 , which represents $11.4 \%$ on a theoretical range of -6 to 6 . The average balance for childcare is 2.95 . The difference between affect balance at work and while taking care of children was -0.30 , which represents $2.5 \%$ on the theoretical range.

- In the 2013 American Time Use Survey (Mokhtarian and Pendyala 2018), the difference in mood at work and at home, "personal \& household", was - 0.41 , which represents $3.4 \%$ of the theoretical range.

- In a study among students and university staff in Australia (Viegas de Lima et al. 2018), the difference in mood at work and at home was -0.7 , which represents $5.8 \%$ of the theoretical range of difference.

The differences found in these studies move in the same direction as our study, people are less happy at work than at home or for most of their other activities, but the difference is much larger in these studies. This means that work tends to have a 'cost' in terms of mood; people typically feel better when they do something other than work.

\subsubsection{Why a smaller difference in mood at work and at home in our study?}

We observed a difference in mood at work and at home of $1 \%$ of the possible scale range in the Happiness Indicator data. Why is this difference smaller than the differences observed in earlier studies? One possible answer is that the working conditions of these self-selected participants in the Netherlands are good and better than those in the other populations studied. Another possibility is that the home life of our respondents is worse than the home life of participants in the other studies. When comparing various subgroups, we will see that the former explanation, good working conditions, is more plausible than the later, worse home life.

\subsection{Differences across subgroups}

The difference in mood at work and at home is the smallest for people older than 50 years, singles, people with a higher education, people working part-time, and people working in the public sector. The difference is the largest among people working in the private sector, fulltime workers and married people. There was no subgroup in which members, on average, felt better at home than at work, except for the group of people older than 50 .

A within-person difference in mood across daily activities may be due to personal and environmental factors. A personal factor can be one's daily rhythm, e.g. morning people feeling less well after 5. Such personal peculiarities are likely to even out in the average scores 
considered here. Hence, the differences in Table 1 reflects variation in environmental conditions, the situations in which people feel better because the situations are more 'liveable' for them. As such, a within-person difference in mood denotes a relative difference in the quality of situational conditions, but does not necessarily indicate its absolute liveability. For example, one may feel better at work than at home, because of a poor marriage.

In this regard, we can imagine, but not prove, that partnered people tend to feel worse at work, Table 2, cases 7, 8 and 9, because they feel even better at home. Such an explanation could also apply for the small difference we found in differences between men and women, Table 3, cases 1 and 2, if women enjoy home life more.

Work conditions are more likely to explain the differences in mood at work and mood at home between workers in the public and private sectors (Table 2, cases 19 and 20), where workers in the private sector feel considerably less well at work than at home $(-0.33)$, while there is no apparent difference in mood at work and at home for public sector workers. Since it is unlikely that public service workers have a better home life, the difference is likely to be due to poorer work conditions in the private sector. The older people and people with a higher education (Table 2, cases 5 and 14), may have better jobs, which will increase their mood at work and make the difference smaller between their mood at work and at home.

\subsection{Information added}

Above in section 1, we mentioned several reasons for why so many employers want to measure the job satisfaction in their workforce periodically. One reason is that the dissatisfaction of workers may signal shortcomings in their work conditions, and call as such for the consideration of improvement of these conditions. Another reason is that employers wonder whether they should invest in raising job satisfaction anyway, expecting that this will a) improve performance at work b) reduce absence at work, c) reduce turnover and d) reduce related demands for financial compensation for dissatisfying work.

This type of demand for information is typically met using retrospective ratings of workers' overall satisfaction at work, the strengths and weakness of which we discussed in the sections 1.1.1 and 1.1.2. In section 3.3 we stated that we found only a moderate correlation between self-reports on the common questions on the degree of job satisfaction and our measurement of the difference in mood at work and at home, which suggests that this measure covers another aspect of job satisfaction. This leads us to ask the following question: Does our new measure provide information on work conditions that employers seek for the above-mentioned reasons?

\subsubsection{Quality of work conditions}

When it comes to indicate the quality of work conditions, our affect-oriented measure is likely to signal issues that common cognitive ratings of overall job satisfaction will miss, that is, shortcomings of which the workers are not aware but that nevertheless thwart the gratification of their needs, such as their latent growth needs in Maslow's (1954) theory of motivation. This affective component can also be captured by the ratings of typical affects at work, but these retrospective ratings tell us more about the workers general satisfaction with life than about their satisfaction with work in particular, these ratings are also vulnerable to recollection bias, as explained in section 1.1.2. Our difference measure bypasses these problems largely (cf. section 1.3.1), be it at the cost of the disadvantages mentioned in section 1.3.2. 
Our difference measure is particularly informative in the case where workers are dissatisfied with their job and their employers wonder whether this is due to poor work conditions or to having hired unhappy people. If dissatisfied workers feel happy at home, the source of their dissatisfaction is apparently not to be found in their general level of dissatisfaction with life, it is more likely to be in their work situation. Our within-person comparison also provides us with a clearer view on the apparent quality of work conditions, since this view is not distorted by endogenic variables, such as a worker's personality traits and response tendencies. In such cases, our mood difference score will provide employers with an indication that something is wrong with the work conditions, although these data will not be able to indicate what is wrong. As such, this indicator is comparable to a fever in relation to illness. Asking workers why they feel bad at work may provide clues, but the workers' attributed reasons for this feeling can be wrong. Finding the sources of low mood with work is also a matter of trial and error.

\subsubsection{Productivity}

A difference in mood at work and at home can also provide additional information when employers consider boosting productivity by raising workers' job satisfaction. In this case, the question arises whether one should either target workers' work conditions, such as by allowing more autonomy and providing company outings, or, by acknowledging that satisfaction with work is largely determined by one's general satisfaction with life, aim at improving workers' personal quality of life, such as by providing flexible work hours or facilitating life coach consultations. The former approach will be most effective if workers feel worse at work than they typically feel at home, while the latter approach is preferable for workers who feel worse at home than at work.

\subsubsection{Absence at work}

Determining the difference in mood at work and at home also provides us with a view on a possible reason for high absence rates. If a worker's mood at work is low while his or her mood at home is high, this can become an incentive for him or her to report sick. In this case, an investment in greater job satisfaction is likely to pay. It can also be that a worker feels better at home in spite of good work conditions and resultant high job satisfaction, and in this case, there is little to gain from taking steps to boost job satisfaction further.

\subsubsection{Turnover and demand for financial compensation}

A difference in mood at work and at home can trigger intentions to quit or lead to demands for better pay. Workers will typically be aware of the differences in their moods and behave accordingly. If they feel bad at work but good at home, they will realize that the source of their low mood at work is likely to be found in their work situation and will look out for another job or press for a higher, compensatory wage. In such cases, our mood difference measure should point employers to consider making investment in better work conditions.

\subsection{Research agenda}

Acknowledging the contribution to the field and limitations of this study, the following questions need to be answered in future research: 
- How common is it for a difference in mood at work and mood during non-work activities: Does work always come at a 'cost'?

- Why do people feel less well at work than at home? What are the work-related drivers of the difference?

- How well does the difference in mood at work and at home correlate with objective indicators of good work conditions, such as autonomy, pay and facilities? Is there a difference with correlations yielded by traditional measures of job satisfaction in this respect?

- How well does the difference in mood at work and at home mood predict personal work performance, work engagement, absenteeism and turnover?

- How well does the difference in mood at work and at home mood predict organizational performance, such as sales, productivity or client satisfaction?

The questions about the relationship between the difference in mood at work and at home and various kinds of indicators of good work conditions and performance can also be addressed when it comes to the difference in mood at work and mood during any non-work activities.

\subsection{Further applications of the difference in mood across situations}

In this paper, we focused on the difference in mood at work and at home and inspected whether understanding this difference can provide us with additional answers to questions that drive job satisfaction research, questions such as ones about the quality of workers' work conditions and drivers of performance at work. Our method can also be applied to study satisfaction with other things. An example close to job satisfaction is school satisfaction, where similar questions are at stake, such as how much mood during school hours depends on the school's conditions and to what degree school performance can be boosted by making school hours more pleasant. It is possible to calculate the difference in mood at school and at home for pupils. Likewise, the method can be applied in fields such as satisfaction with marriage and satisfaction with outdoor living environment. It is possible to calculate the difference in mood during time spent with spouse and without spouse, and the difference in mood during time spent outdoor and indoor. In the case of consumer satisfaction, the method could be applied in research on determinants and consequences of satisfaction with time-intensive consumer items, such as housing and holidays.

\section{Conclusions}

Techniques of multiple-moment assessment enable us to examine the differences in how well an individual feels across different conditions. An exploration of differences in mood at work and at home reveals that people tend to feel less well at work. This difference in momentary mood is largely independent of retrospective reports of job satisfaction, which suggests that a different aspect of job satisfaction is measured. As such, the technique presented here opens a new window on job satisfaction and the questions behind common measurement of that. This is something that needs to be addressed in future research. 


\section{Appendix 1}

Table 4 Number of Respondents and Observations per Subgroup

\begin{tabular}{|c|c|c|}
\hline & Respondents & Observations \\
\hline \multicolumn{3}{|l|}{ Gender } \\
\hline Men & 235 & 5,550 \\
\hline Women & 1057 & 24,484 \\
\hline \multicolumn{3}{|l|}{ Age } \\
\hline Younger than 35 years & 475 & 9,917 \\
\hline $35-50$ years & 539 & 14,149 \\
\hline Older than 50 years & 278 & 5,968 \\
\hline \multicolumn{3}{|l|}{ Marital status } \\
\hline Single with Children & 119 & 3,551 \\
\hline Single without Children & 359 & 7,397 \\
\hline Partner with Children & 293 & 7,618 \\
\hline Partner without Children & 349 & 7,933 \\
\hline \multicolumn{3}{|l|}{ Family Income } \\
\hline Below Average & 304 & 7,376 \\
\hline Average & 477 & 10,534 \\
\hline Above Average & 510 & 12,112 \\
\hline \multicolumn{3}{|l|}{ Education } \\
\hline Lower educated & 491 & 10,572 \\
\hline High educated & 801 & 19,462 \\
\hline \multicolumn{3}{|l|}{ Working status } \\
\hline Working Part-time & 563 & 12,381 \\
\hline Working Full-time & 688 & 15,969 \\
\hline \multicolumn{3}{|l|}{ Job status } \\
\hline Paid & 1,120 & 25,746 \\
\hline Unpaid & 161 & 3,911 \\
\hline \multicolumn{3}{|l|}{ Sector } \\
\hline Public & 820 & 19,890 \\
\hline Private & 298 & 6,867 \\
\hline
\end{tabular}

Note: Please note that some people did not provide all the necessary information in the first questionnaire. Hence, the number of respondents is lower than 1,410 for most groups of variables. 


\section{Appendix 2}

Table 5 Mood at Home and Mood at Work per Subgroup

\begin{tabular}{|c|c|c|c|}
\hline & Mood at Home & Mood at Work & Observations \\
\hline \multicolumn{4}{|l|}{ Gender } \\
\hline Men & 6.74 & 6.76 & 5,550 \\
\hline Women & 6.80 & 6.72 & 24,484 \\
\hline \multicolumn{4}{|l|}{ Age } \\
\hline Younger than 35 years & 6.79 & 6.63 & 9,917 \\
\hline $35-50$ years & 6.78 & 6.73 & 14,149 \\
\hline Older than 50 years & 6.81 & 6.82 & 5,968 \\
\hline \multicolumn{4}{|l|}{ Marital Status } \\
\hline Single with Children & 6.74 & 6.79 & 3,551 \\
\hline Single without Children & 6.43 & 6.55 & 7,397 \\
\hline Partner with Children & 6.84 & 6.62 & 7,618 \\
\hline Partner without Children & 7.09 & 6.89 & 7,933 \\
\hline \multicolumn{4}{|l|}{ Family Income } \\
\hline Below Average & 6.49 & 6.60 & 7,376 \\
\hline Average & 6.74 & 6.53 & 10,534 \\
\hline Above Average & 7.01 & 6.96 & 12,112 \\
\hline \multicolumn{4}{|l|}{ Education } \\
\hline Lower educated & 6.76 & 6.70 & 10,572 \\
\hline High educated & 6.81 & 6.73 & 19,462 \\
\hline \multicolumn{4}{|l|}{ Working status } \\
\hline Part-time & 6.76 & 6.83 & 12,381 \\
\hline Full-time & 6.82 & 6.66 & 15,969 \\
\hline \multicolumn{4}{|l|}{ Job status } \\
\hline Paid Job & 6.84 & 6.74 & 25,746 \\
\hline Unpaid Job & 6.52 & 6.64 & 3,911 \\
\hline \multicolumn{4}{|l|}{ Sector } \\
\hline Public & 6.84 & 6.85 & 15,829 \\
\hline Private & 6.83 & 6.54 & 6,867 \\
\hline
\end{tabular}

Note: All averages are duration-weighted. Note: Cases for which information on subgroup category was not available were omitted from the analysis.

Open Access This article is licensed under a Creative Commons Attribution 4.0 International License, which permits use, sharing, adaptation, distribution and reproduction in any medium or format, as long as you give appropriate credit to the original author(s) and the source, provide a link to the Creative Commons licence, and indicate if changes were made. The images or other third party material in this article are included in the article's Creative Commons licence, unless indicated otherwise in a credit line to the material. If material is not included in the article's Creative Commons licence and your intended use is not permitted by statutory regulation or exceeds the permitted use, you will need to obtain permission directly from the copyright holder. To view a copy of this licence, visit http://creativecommons.org/licenses/by/4.0/.

\section{References}

Bakker, A., Burger, M., van Haren, P., Oerlemans, W., \& Veenhoven, R. (2020). Raise of happiness following raised awareness of how happy one feels: A follow-up of repeated users of the Happiness Indicator website. International Journal of Applied Positive Psychology, 5, 153-187.

Bakker, A. B., \& Oerlemans, W. G. (2016). Momentary work happiness as a function of enduring burnout and work engagement. The Journal of Psychology, 150(6), 755-778. 
Bergkvist, L., \& Rossiter, J. R. (2007). The predictive validity of multiple-item versus single-item measures of the same constructs. Journal of Marketing Research, 44(2), 175-184.

Brief, A. P., Burke, M. J., George, J. M., Robinson, B. S., \& Webster, J. (1988). Should negative affectivity remain an unmeasured variable in the study of job stress? Journal of Applied Psychology, 73(2), 193-198.

Burke, M. J., Brief, A. P., George, J. M., Roberson, L., \& Webster, J. (1989). Measuring affect at work: confirmatory analyses of competing mood structures with conceptual linkage to cortical regulatory systems. Journal of Personality and Pocial Psychology, 57(6), 1091-1102.

Bylsma, L. M., Taylor-Clift, A., \& Rottenberg, J. (2011). Emotional reactivity to daily events in major and minor depression. Journal of Abnormal Psychology, 120(1), 155-167.

Csikszentmihalyi, M., \& Larson, R. (2014). Validity and reliability of the experience-sampling method. In M. Csikszentmihalyi (Ed.), Flow and the foundations of positive psychology (pp. 35-54). Dordrecht: Springer.

Cummins, R. A. (2014). Core Affect. In A. C. Michalos (Ed.), Encyclopedia of quality of life and well-being research. Dordrecht: Springer.

Daniels, K. (2000). Measures of five aspects of affective well-being at work. Human Relations, 53(2), 275-294.

Dockray, S., Grant, N., Stone, A. A., Kahneman, D., Wardle, J., \& Steptoe, A. (2010). A comparison of affect ratings obtained with ecological momentary assessment and the Day Reconstruction Method. Social Indicators Research, 99(2), 269-283.

Fisher, C. D. (2003). Why do lay people believe that satisfaction and performance are correlated? Possible sources of a commonsense theory. Journal of Organizational Behavior: The International Journal of Industrial, Occupational and Organizational Psychology and Behavior, 24(6), 753-777.

Headey, B., Veenhoven, R., \& Wearing, A. (1991). Top-down versus bottom-up theories of subjective wellbeing. Social Indicators Research, 24(1), 81-100.

Ironson, G. H., Smith, P. C., Brannick, M. T., Gibson, W. M., \& Paul, K. B. (1989). Construction of a Job in General scale: A comparison of global, composite. and specific measures. Journal of Applied psychology, 74(2), 193-200.

Jones, M. D. (2006). Which is a better predictor of job performance: Job satisfaction or life satisfaction? Journal of Behavioral and Applied Management, 8(1), 20-42.

Kainulainen, S., Saari, J., \& Veenhoven, R. (2018). Life-satisfaction is more a matter of feeling well than having what you want: Tests of Veenhoven's theory. International Journal of Happiness and Development, 4, 209235.

Kahneman, D. (1999). Objective happiness. In D. Kahneman, E., Diener \& N. Schwarz (Eds.), Well-being: The foundations of hedonic psychology (pp. 3 -25). New York: Russell Sage Foundation.

Kahneman, D., Krueger, A. B., Schkade, D. A., Schwarz, N., \& Stone, A. A. (2004). A survey method for characterizing daily life experience: The day reconstruction method. Science, 306(5702), 1776-1780.

Kim, J., Kikuchi, H., \& Yamamoto, Y. (2013). Systematic comparison between ecological momentary assessment and day reconstruction method for fatigue and mood states in healthy adults. British Journal of Health Psychology, 18(1), 155-167.

Lancée, S., Veenhoven, R., \& Burger, M. (2017). Mood during commute in the Netherlands: What way of travel feels best for what kind of people? Transportation Research Part A: Policy and Practice, 104, 195-208.

Larson, R., \& Csikszentmihalyi, M. (1983). The experience sampling method. In H. Reis (Ed.), New Directions for Methodology of Social and Behavioral Science (pp. 41-53). San Francisco: Jossey-Bass.

Ludwigs, K., \& Erdtmann, S. (2019). The happiness analyzer-Developing a new technique for measuring subjective well-being. International Journal of Community Well-Being, 1(2), 101-114.

Maslow, A. H. (1954). Motivation and personality. New York, NY: Harper \& Row.

Mokhtarian, P., \& Pendyala, R. M. (2018). Travel satisfaction and Wellbeing. In M. Friman, D. Ettema, \& L. E. Olsson (Eds.), Quality of life and daily travel (pp. 17-39). Cham: Springer.

Russell, J. A. (1980). A circumplex model of affect. Journal of Personality and Social Psychology., 39, 11611178.

Scollon, C. N., Prieto, C. K., \& Diener, E. (2009). Experience sampling: promises and pitfalls, strength and weaknesses. In E. Diener (Ed.), Assessing well-being (pp. 157-180). Dordrecht: Springer.

Van Katwyk, P. T., Fox, S., Spector, P. E., \& Kelloway, E. K. (2000). Using the Job-Related Affective WellBeing Scale (JAWS) to investigate affective responses to work stressors. Journal of Occupational Health Psychology, 5(2), 219-230.

Veenhoven, R. (2009). How do we access how happy we are? In: Dutt, A. K. \& Radcliff, B. (eds.), Happiness, economics and politics: Towards a multidisciplinary approach, Edward Elger Publishers, Cheltenham UK, Chapter 3, pp 45-69.

Viegas de Lima, I., Abou Zeid, M., Kutadinata, R., Navidi, Z., Winter, S. Zoa, F. \& Ben-Avika, M. (2018). Dynamic modelling of activity happiness: An investigation of the intra-activity hedonic treadmill In M. Friman, D. Ettema \& L.E. Olsson (Eds.), Quality of life and daily travel (pp. 95-118). Cham: Springer. 
Warr, P. (1990). The measurement of well-being and other aspects of mental health. Journal of Occupational Psychology, 63, 193-210.

Weiss, D. J., Dawis, R. V., \& England, G. W. (1967). Manual for the Minnesota satisfaction questionnaire. Minnesota Studies in Vocational Rehabilitation, 22, 120.

Weiss, H. M. (2002). Deconstructing job satisfaction: Separating evaluations, beliefs and affective experiences. Human Resource Management Review, 12(2), 173-194.

Zelenski, J. M., Murphy, S. A., \& Jenkins, D. A. (2008). The happy-productive worker thesis revisited. Journal of Happiness studies, 9(4), 521-537.

Publisher's Note Springer Nature remains neutral with regard to jurisdictional claims in published maps and institutional affiliations.

\section{Affiliations}

\section{Renaud Gaucher $^{1} \cdot$ Martijn Burger $^{1} \cdot$ Ruut Veenhoven ${ }^{1,2}$}

1 Erasmus Happiness Economics Research Organization EHERO, Erasmus University Rotterdam, Rotterdam, Netherlands

2 North-West University in South Africa, Opentia Research Program, Vanderbijlpark, South Africa 